\title{
ALTERAÇÕES FISIOLÓGICAS, BIOQUÍMICAS E MICROBIOLÓGICAS DE ALIMENTOS MINIMAMENTE PROCESSADOS
}

\author{
ALEXANDRE PORTE * \\ LUCIANA HELENA MAIA **
}

\begin{abstract}
Apresenta breve revisão bibliográfica sobre as alterações fisiológicas, bioquímicas e microbiológicas que comumente acometem os alimentos minimamente processados. Conclui que o aperfeiçoamento das condições de processamento e o desenvolvimento de embalagens apropriadas para as características composicionais do produto propiciará produção promissora de alimentos minimamente processados.
\end{abstract}

\section{INTRODUÇÃO}

Os alimentos minimamente processados (AMP), tais como frutas e hortaliças intactas, deterioram-se após a colheita devido a alterações fisiológicas. Entretanto, as lesões provocadas durante o processamento promovem a descompartimentalização celular e possibilitam o contato de enzimas e substratos, que originam modificações bioquímicas, como escurecimento, formação de odores desagradáveis e perda da textura original. Além disso, o descascamento e o corte de frutas e vegetais favorecem a colonização dos tecidos vegetais por microrganismos deterioradores e patogênicos (VAROQUAUX \& WILEY, 1997). Assim, um dos objetivos da tecnologia de alimentos é conseguir estender o shelf life destes produtos. Contudo dois problemas básicos dificultam a extensão da vida de prateleira dos AMP. Primeiro, os tecidos vegetais estão vivos, respirando e muitas reações químicas estão acontecendo, e segundo, a proliferação de microrganismos que precisa ser retardada. $O$ controle destes dois parâmetros é crítico para a produção destes produtos, concomitantemente com o desenvolvimento de embalagens apropriadas para atingir as condições ideais de armazenamento e conservação (KING JR \& BOLIN, 1989).

* Nutricionista, Doutorando em Ciências, Universidade Federal do Rio de Janeiro (UFRJ) RJ. (e-mail: alexandrepor@zipmail.com.br).

** Economista Doméstica, Doutoranda em Ciências, UFRJ, RJ.

(e-mail: lucianahmaia@zipmail.com.br). 
Fatores extrínsecos, como a temperatura e a composição atmosférica são fundamentais para retardar desordens fisiológicas, bioquímicas e microbiológicas dos alimentos minimamente processados, que afetam suas características sensoriais.

Sob o ponto de vista microbiológico, os vegetais estão entre os alimentos mais seguros. Não obstante, existem condições extrínsecas e intrínsecas ao alimento que podem permitir ou favorecer o crescimento de microrganismos deterioradores e até patogênicos. Ao mesmo tempo existem fatores que dificultam as alterações provocadas por estes microrganismos.

O presente trabalho teve por objetivo enfocar as principais alterações fisiológicas, bioquímicas e microbiológicas que acometem os alimentos minimamente processados, cujo controle é um ponto crítico para a produção deste tipo de produto.

\section{ALTERAÇÕES FISIOLÓGICAS E BIOQUÍMICAS}

\section{- Metabolismo respiratório}

A respiração vegetal consiste na oxidação de açúcares e ácidos orgânicos para obtenção de energia, que produz como resíduos dióxido de carbono $\left(\mathrm{CO}_{2}\right)$ e água (VAROQUAUX \& WILEY, 1997).

As principais manifestações fisiológicas, provenientes da ruptura dos tecidos vegetais são o aumento na velocidade de respiração, e, em alguns casos, a produção de etileno (VAROQUAUX \& WILEY, 1997). A taxa respiratória dos alimentos minimamente processados é aumentada de 3 a 7 vezes, em relação ao tecido intacto, o que se traduz em rápido consumo de oxigênio dentro da embalagem (VAROQUAUX \& WILEY, 1997).

A diminuição do teor de $\mathrm{O}_{2}$ disponível para frutas e vegetais reduz a taxa respiratória (produção de $\mathrm{CO}_{2}$ /consumo de $\mathrm{O}_{2}$ ), que geralmente requer no mínimo de 1 a $3 \%$ de oxigênio, dependendo do produto, para evitar a mudança de respiração aeróbica para anaeróbica. Sob condições anaeróbicas, a via glicolítica substitui o ciclo de Krebs como a principal fonte de energia para os vegetais. O ácido pirúvico é descarboxilado para formar acetaldeído, e a partir deste, $\mathrm{CO}_{2}$ e etanol, resultando no desenvolvimento de sabor indesejável, rompimento e escurecimento dos tecidos (KADER, 1986).

A reação de redução do metabolismo respiratório, que ocorre em baixos teores de $\mathrm{O}_{2}$, pode ser resultado do decréscimo da atividade de algumas enzimas específicas, como a polifenoloxidase e a acidoglicolicoxidase ou ácido ascórbico oxidase, cujas afinidades pelo oxigênio pode ser de 5 a 6 
vezes menor que a da citocromo oxidase. A atividade da enzima citocromo oxidase não é suprimida em baixos teores de oxigênio, devido à sua alta afinidade com o mesmo (WEICHMANN, 1987).

Em atmosfera de armazenamento com baixos teores de oxigênio, a quebra de ácido ascórbico é inibida. A oxidação de vitamina $C$ é regulada, principalmente, pelo ácido ascórbico oxidase e outras enzimas que apresentam baixa afinidade com o oxigênio. Por isso, em baixos teores deste gás ocorre retardamento na mudança de ácido ascórbico para ácido desidroascórbico (WEICHMANN, 1987).

Altas concentrações de $\mathrm{CO}_{2}(>20 \%)$ causam injúrias nos vegetais e, dependendo do produto e da concentração de oxigênio pode resultar em acumulação de etanol e acetaldeído nos tecidos, porém, em níveis adequados reduzem a taxa respiratória de frutas e vegetais frescos (KADER, 1986; HERNER, 1987).

O armazenamento de frutas e vegetais em concentrações de 5 a $20 \%$ de $\mathrm{CO}_{2}$ pode causar mudança na atividade de enzimas específicas do metabolismo respiratório, com efeito de desacoplamento na fosforilação oxidativa. Estudo dos efeitos de teores de $\mathrm{CO}_{2}$ em intermediários do ciclo de Krebs e enzimas evidenciaram que houve acumulação de ácido succínico, devido a inibição da atividade da desidrogenase succínica em maçãs (MONNING, 1983). Deste modo, níveis elevados de $\mathrm{CO}_{2}$ inibem enzimas do ciclo de Krebs, e portanto, a respiração aeróbica, induzindo a respiração anaeróbica. Segundo BURTON (1974), citado por VAROQUAUX \& WILEY (1997), estes valores seriam de 0,2\% no interior da célula e de 1 a $3 \%$ no exterior do produto. Não obstante, são valores gerais que podem variar conforme o tipo de alimento e condições de cultivo (irrigação, clima, fertilização, etc.) (VAROQUAUX \& WILEY, 1997).

A dissolução de $\mathrm{CO}_{2}$ em excesso no meio intracelular altera o $\mathrm{pH}$, afetando de forma negativa a atividade catalítica das enzimas (VAROQUAUX \& WILEY, 1997).

A atmosfera modificada e/ou controlada pode reduzir o consumo de oxigênio e a produção de $\mathrm{CO}_{2}$ (VAROQUAUX \& WILEY, 1997). A redução do $\mathrm{O}_{2}$ e/ou elevação do $\mathrm{CO}_{2}$ para reduzir a taxa respiratória de frutas e vegetais minimamente processados tem sido reconhecida como a principal razão dos efeitos benéficos da atmosfera modificada e/ou controlada. Porém, trata-se de simplificação, já que a deterioração pós-colheita de vegetais e frutas frescas pode ser causada por muitos fatores adicionais à taxa respiratória, que incluem: mudanças metabólicas (mudanças bioquímicas associadas com o metabolismo respiratório, biossíntese e ação do etileno e mudanças composicionais), injúrias físicas, perda de água, desordens fisiológicas e microbiológicas (KADER, 1986). 
A relação entre a composição da atmosfera modificada e a velocidade de respiração ainda não está clara (VAROQUAUX \& WILEY, 1997).

A temperatura também exerce papel fundamental na respiração de vegetais, sendo que sua diminuição e estabilização (sem variações) também reduz a taxa respiratória e atrasa o processo de senescência de frutas e hortaliças. Segundo SCANDELLA (1988), citado por VAROQUAUX \& WILEY (1997), a legislação francesa exige o limite máximo de $4{ }^{\circ} \mathrm{C}$ para a refrigeração de $\mathrm{AMP}$ e a inglesa de 0 a $8^{\circ} \mathrm{C}$.

\section{- Biossíntese e ação do etileno}

O etileno, composto volátil de dois carbonos, é produzido endogenamente, talvez, por todas as plantas. Em concentrações tão baixas quanto $0,1 \mu \mathrm{L} / \mathrm{L}$, o etileno pode induzir uma série de respostas fisiológicas, incluindo amadurecimento, senescência e desordens fisiológicas (WATADA, 1986).

A redução de teores de oxigênio abaixo de $8 \%$ diminui a produção de etileno pelas frutas frescas e vegetais. $O$ oxigênio é necessário para a produção e ação do etileno. Sob condições anaeróbicas, a conversão de 1ácido carboxílico-1-aminociclopropano (ACC) a etileno é inibida, resultando na acumulação de ACC no tecido, já que os passos iniciais da biossíntese de etileno, a partir da metionina ocorrem na ausência de $\mathrm{O}_{2}$ (WATADA, 1986). Em elevadas concentrações de $\mathrm{CO}_{2}$ pode haver aumento na produção de etileno devido a ocorrência de injúrias fisiológicas no tecido. Todavia, o mecanismo de indução da produção de etileno não é bem conhecido (WATADA, 1986).

$\mathrm{O}_{2}$ previne ou retarda os efeitos prejudiciais do etileno em frutas e vegetais frescos, tais como a perda de firmeza e a incidência de desordens fisiológicas. O modo de ação do $\mathrm{CO}_{2}$ na inibição ou redução dos efeitos do etileno ainda não está clara, mas BURG \& BURG (1967), citados por KADER (1986), sugerem que o $\mathrm{CO}_{2}$ compete com o etileno pelo sítio de ligação.

A produção de etileno por frutas e hortaliças processadas pode ser incrementada em até 20 vezes, quando comparada com vegetal intacto (VAROQUAUX e WILEY, 1997).

HARVEY (1925; 1928), citado por WATADA (1986), estudou o uso de etileno em várias frutas e verificou perda de clorofila, desenvolvimento de cor de maturação, amolecimento dos tecidos, desenvolvimento de sabor e início da atividade da enzima proteoclástica.

O etileno estimula a síntese de enzimas envolvidas com a maturação das frutas e pode causar a perda de firmeza das mesmas, provavelmente, devido a ativação de enzimas que hidrolisam a parede celular (WATADA, 
1986). Também está relacionado com o incremento da descoloração da cor verde de vegetais folhosos (LOUGHEED, MURR \& TOIVONEN, 1987), talvez devido ao aumento da atividade da clorofilase (VAROQUAUX \& WILEY, 1997).

O dióxido de carbono em elevadas concentrações inibe a ação do etileno sobre os tecidos vegetais e sua formação ocorre a partir da oxidação do ácido-1-aminociclopropano carboxílico, pela baixa pressão parcial de oxigênio (VAROQUAUX \& WILEY, 1997).

\section{- Mau odor}

O mau odor encontrado em hortaliças está intimamente relacionado com a peroxidação enzimática de ácidos graxos insaturados, catalisada por lipoxidases, que produzem aldeídos e cetonas, como o n-hexanal, resultante da quebra de hidroperóxidos (VAROQUAUX \& WILEY, 1997).

Os próprios hidroperóxidos, devido a sua instabilidade química, podem comprometer a integridade de membranas celulares e proteínas, facilitando outras desordens fisiológicas (VAROQUAUX \& WILEY, 1997).

\section{- Escurecimento enzimático e químico}

O escurecimento dos vegetais pode ser enzimático ou químico (VAROQUAUX \& WILEY, 1997).

As polifenoloxidases constituem a classe de enzimas envolvidas no escurecimento de vegetais e pequena redução no $\mathrm{pH}$ pode diminuir em até $50 \%$ a atividade deste tipo de enzima (VAROQUAUX \& WILEY, 1997).

A clorofila pode ser decomposta por várias enzimas (clorofiloxidase, clorofilases e hidrolases ácidas com atividade lipolítica) (VAROQUAUX \& WILEY, 1997).

Baixas temperaturas podem reduzir a atividade de enzimas como a tirosinase e difenoloxidase, contribuindo para a conservação da cor dos vegetais. Contudo, ainda que baixas, temperaturas inadequadas de armazenamento provocam injúrias que afetam a cor e a qualidade de diversos alimentos, o que ressalta a importância da manutenção de temperaturas ótimas em toda a cadeia de produção e comercialização destes produtos (VAROQUAUX \& WILEY, 1997).

A diminuição da concentração de oxigênio reduz a velocidade de reação de enzimas que catalisam oxidação, acarretando o escurecimento, como as polifenoloxidases, visto que o oxigênio é um de seus substratos. Por isso, o acondicionamento sob vácuo ou nitrogênio tende a retardar o 
escurecimento dos produtos, mas pode provocar a fermentação láctica (VAROQUAUX \& WILEY, 1997).

As orto-benzoquinonas, muito reativas e instáveis em soluções aquosas, são convertidas em compostos fenólicos sob ação de agentes redutores, como ácido ascórbico, além de serem polimerizadas a melaninas (VAROQUAUX \& WILEY, 1997). As melaninas são pigmentos poliméricos responsáveis pela coloração escura.

As clorofilas são convertidas em feofitinas em pH ácido, alterando a cor de vegetais como o brócolis (VAROQUAUX \& WILEY, 1997).

A oxidação dos carotenóides contribui para a perda da coloração natural de vários alimentos, em presença de alta concentração de oxigênio na atmosfera de armazenamento (VAROQUAUX \& WILEY, 1997).

\section{- $\quad$ Perda da Textura}

A degradação da textura, deve-se a ação de proteases e enzimas pectinolíticas dos compostos da parede celular para ao interior do produto (VAROQUAUX \& WILEY, 1997).

Altas concentrações de $\mathrm{CO}_{2}$ inibem a degradação de textura em morangos, enquanto que não altera o amolecimento de rodelas de kiwi, sugerindo que a concentração gasosa não exerce efeito sobre as enzimas proteolíticas e pectinolíticas (VAROQUAUX \& WILEY, 1997).

\section{- Injúrias físicas}

As frutas e vegetais precisam apresentar excelente qualidade (ausência de injúrias e danos mecânicos) para serem parcialmente processadas. Qualquer rompimento no tecido induz atividades fisiológicas, reações bioquímicas e/ou infecções por patógenos, resultando na deterioração do produto.

No processamento parcial de frutas e vegetais, as etapas do processo como corte, descascamento e outras ações físicas causam injúrias e danos aos tecidos. No entanto, estas ações físicas são necessárias no preparo de produtos frescos para consumo direto (HUXSOLL \& BOLIN, 1989).

Durante a senescência dos tecidos vegetais, as estruturas celulares e organelas sofrem alterações porque as reações degradativas tornam-se maiores que as reações biosintéticas neste estágio. Mudanças como a quebra de lipídios e a desorganização das membranas das células que, com a continuidade do processo de senescência e conseqüente enfraquecimento da estrutura celular, torna o tecido das frutas maduras muito susceptível ao processo de deterioração, induzido pelas injúrias 
causadas pelas ações físicas do processamento (WATADA, ABE \& YAMUCHI, 1990).

Os tecidos fatiados, cuja superfície de exposição é maior, apresentam maiores taxas de respiração e, conseqüentemente, maiores alterações fisiológicas, bioquímicas e microbiológicas que o tecido inteiro.

\section{- $\quad$ Perda de água}

A perda de água pode ser uma das principais causas de deterioração dos AMP, já que resulta em perdas quantitativas, perdas na aparência (murchamento), na textura (amolecimento) e na qualidade nutricional. A perda de água pelos AMP pode ser minimizada pela atmosfera modificada ou controlada, devido a elevada umidade relativa propiciada (KADER, 1986).

\section{ALTERAÇÕES MICROBIOLÓGICAS}

As alterações microbiológicas que ocorrem em vegetais variam segundo a composição da microflora de cada alimento, que por sua vez está relacionada com outros fatores. O ambiente, a manipulação, a água disponível e a umidade, a temperatura, a atmosfera e a acidez são os mais importantes. De maneira geral as alterações são causadas por: mesófilos, bactérias ácido lácticas, coliformes totais e fecais, bactérias pectinolíticas, leveduras e fungos (WATADA, KO \& MINOTT, 1996).

\section{- Fatores Relacionados com o Crescimento Microbiano}

O ambiente é o primeiro fator contaminante dos alimentos. $\mathrm{O}$ solo, por exemplo, é rico em bactérias gram-positivas e fungos, que podem contaminar os alimentos diretamente ou serem transportados pelo vento ou por insetos. $O$ ar serve mais como veículo do que como meio de crescimento. A chuva pode arrastar terra para produtos cultivados próximo ao solo e elevar sua carga microbiana, além de aumentar a umidade e favorecer o crescimento de fungos em até 72\% (BRACKETT, 1997).

A manipulação permite a contaminação cruzada pelos trabalhadores e determinados recipientes com superfícies desiguais ou salientes podem rasgar hortaliças e cascas de frutas. Estes danos provocam a liberação do suco nutritivo, que permite o crescimento microbiano nos equipamentos e nos próprios alimentos. Tratamentos como cortes, que expõem grandes superfícies (em rodelas, por exemplo), podem provocar proliferação microbiana 6 a 7 vezes superiores que em alimentos intactos. Mesmo microrganismos não deteriorantes em outras condições, podem ocasionar a degradação do produto após a perda da proteção natural que as cascas representam (BRACKETT, 1997). 
As frutas e hortaliças apresentam atividade de água (Aw) em torno de 0,95 ou maior, permitindo o crescimento de muitos microrganismos. Baixa umidade no interior da embalagem dificulta o crescimento de bactérias, mas promove a rápida desidratação do alimento e pode selecionar fungos. Já alta umidade facilita a condensação de gotículas sobre os produtos, servindo como meio difusivo de microrganismos e como caldo de cultivo (dissolve carboidratos liberados dos alimentos) (BRACKETT, 1989; BRACKETT, 1997; NGUYEN-THE \& CARLIN, 1994).

Segundo BRACKETT (1997) a temperatura é, provavelmente, o fator mais importante que afeta o crescimento de microrganismos. Como as frutas e hortaliças são cultivadas e colhidas em temperatura ambiente, nos países de clima quente como o Brasil, é comum a predominância de bactérias mesofílicas. Entretanto, o tratamento de refrigeração que ocorre na maioria dos alimentos minimamente processados pode modificar este quadro, contribuindo para a predominância de psicotróficos. Temperaturas de refrigeração exercem efeito de redução da proliferação microbiana em frutas e hortaliças (VAROQUAUX \& WILEY, 1997).

A atmosfera no interior da embalagem afeta não apenas o metabolismo do alimento, como visto anteriormente, mas é fundamental na seleção da microflora presente.

O efeito bacteriostático de elevadas concentrações de $\mathrm{CO}_{2}$ e reduzidas concentrações de $\mathrm{O}_{2}$ é bem conhecido há mais de um século (DANIELS, KRISHNAMURTHI \& RIZVI, 1985), mas o impacto efetivo sobre os microrganismos depende do organismo em si, da concentração do gás, da temperatura e da tolerância fisiológica do alimento. Geralmente, são necessárias concentrações entre cinco por cento e vinte e cinco por cento e os efeitos variam em temperaturas diferentes (BRACKETT, 1997). Baixas temperaturas aumentam a solubilidade do dióxido de carbono, acentuando seus efeitos bacteriostáticos, cuja ação máxima ocorre em $1^{\circ} \mathrm{C}$ (DANIELS, KRISHNAMURTHI \& RIZVI, 1985).

$\mathrm{O} \mathrm{CO}_{2}$ interfere no metabolismo celular dos microrganismos mais sensíveis, como os gram-negativos, aeróbios e bactérias psicotróficas (entre as quais Pseudomonas sp.) e bolores (DANIELS, KRISHNAMURTHI \& RIZVI, 1985; HINTLIAN \& HOTCHKISS, 1986). Entretanto, altas concentrações podem selecionar anaeróbios facultativos ou obrigatórios, como as bactérias lácticas e as bactérias acéticas ou de eucariotas unicelulares.

Possivelmente o $\mathrm{CO}_{2}$ aumenta a fase lag e o tempo de geração no ciclo de crescimento dos microrganismos, mas outros mecanismos são propostos (DANIELS, KRISHNAMURTHI \& RIZVI, 1985; HINTLIAN \& HOTCHKISS, 1986). O primeiro refere-se ao $\mathrm{CO}_{2}$ como agente que desloca o oxigênio, mas quando este é substituído por nitrogênio, o mesmo efeito 
bacteriostático não ocorre. Desta forma, parece que a redução do oxigênio disponível não constitui fator limitante do crescimento dos microrganismos, mas sim a presença de $\mathrm{CO}_{2}$ (DANIELS, KRISHNAMURTHI \& RIZVI, 1985). $\mathrm{O}$ segundo mecanismo proposto é a acidificação do meio. Quando o $\mathrm{CO}_{2}$ é dissolvido em solução, algumas reações primárias ocorrem:

- pequena parte (aproximadamente 2 \%) converte-se em ácido carbônico:

- $\mathrm{CO}_{2}+\mathrm{H}_{2} \mathrm{O} \rightarrow \mathrm{H}_{2} \mathrm{CO}_{3} \quad \mathrm{pH}<5$

- e uma fração deste ácido carbônico dissocia-se em bicarbonato mais íon:

- $\mathrm{H}_{2} \mathrm{CO}_{3} \rightarrow \mathrm{HCO}_{3}^{-}+\mathrm{H}^{+} \quad$ pH entre 8 e 9,5

- que por sua vez também dissocia-se em carbonato mais cátion:

$-\mathrm{HCO}_{3}{ }^{-} \rightarrow \mathrm{CO}_{3}{ }^{-}+\mathrm{H}^{+} \quad \mathrm{pH}>11,5$

Como os alimentos minimamente processados incluem-se na faixa de $\mathrm{pH}$ favorável para a formação de ácido carbônico, este ácido moderado alteraria o pH do meio e retardaria a proliferação microbiana. Entretanto, este mecanismo também não é amplamente aceito, porque outros ácidos que provocam o mesmo efeito acidificante nas células não exercem o efeito bacteriostático do ácido carbônico (DANIELS, KRISHNAMURTHI \& RIZVI, 1985). Outro mecanismo envolve o poder penetrante do $\mathrm{CO}_{2}$ nas células, cerca de 30 vezes mais rápido que o oxigênio. Este efeito, junto com os íons bicarbonato afetariam a estrutura da membrana celular, desidratando-a e aumentando sua permeabilidade a íons que desbalanceariam o meio intracelular (DANIELS, KRISHNAMURTHI \& RIZVI, 1985). O último mecanismo seria o efeito inibitório de $\mathrm{CO}_{2}$ sobre enzimas do metabolismo energético de microrganismos. Altas concentrações de $\mathrm{CO}_{2}$ inibem a ação de oxaloacetato descarboxilase, da fumarato e succinato desidrogenase e da citocromo c oxidase, aumentando a formação de succinato. Também eleva a atividade da ATPase mitocondrial. $O$ aumento da ATPase mitocondrial aumenta o desacoplamento na fosforilação oxidativa da cadeia respiratória, resultando no decréscimo do total de ATP formados, e por conseguinte de toda a energia necessária para o crescimento (DANIELS, KRISHNAMURTHI \& RIZVI, 1985).

O enriquecimento da atmosfera de armazenamento com $\mathrm{CO}_{2}$, em temperatura de 6 a $10^{\circ} \mathrm{C}$ produz crescimento mais lento da flora mesofílica em comparação com atmosfera contendo ar, além de crescimento mais rápido da flora ácido-láctica (VAROQUAUX \& WILEY, 1997; HINTLIAN \& HOTCHKISS, 1986). Isto porque $0 \mathrm{CO}_{2}$ inibe alguns tipos de microrganismos, mas não apresenta efeito direto sobre outros (HINTLIAN \& HOTCHKISS, 1986).

HINTLIAN \& HOTCHKISS (1986) alertam que, qualquer que seja a atmosfera presente existe risco microbiológico potencial, e portanto, não 
substituem a refrigeração. Inclusive, pode inibir o crescimento de microrganismos deterioradores, mas permitir a proliferação de patógenos, que sem os sinais deteriorativos comuns podem ser ingeridos com os alimentos. Por isso, o aumento da vida de prateleira dos alimentos minimamente processados deve se visto criteriosamente.

As frutas e hortaliças apresentam características químicas diferentes, que se refletem na composição da microflora presente em cada uma (Tabela 1). As hortaliças apresentam elevada quantidade de água e de nutrientes e $\mathrm{pH}$ neutro. Assim, as bactérias tornam-se os microrganismos preponderantes nestes alimentos, pois seu crescimento é mais rápido que o de microrganismos eucariotas (BRACKETT, 1997). Entre as bactérias, as gram-negativas são as mais isoladas, sendo que as famílias pseudomonáceas e enterobacteriaceae representam a maioria, principalmente os gêneros Pseudomonas sp. e Erwinia sp. O gênero Pseudomonas sp. apresenta atividade pectinolítica, mas não resiste a altas concentrações de $\mathrm{CO}_{2}$ (VAROQUAUX \& WILEY, 1997).

\section{TABELA 1 - MICRORGANISMOS MAIS COMUNS EM HORTALIÇAS E FRUTAS}

\begin{tabular}{|c|c|c|c|}
\hline Alimentos & Bactérias & Leveduras & Bolores \\
\hline Hortaliças & $\begin{array}{l}\text { - Gram-negativas } \\
\text { Pseudomonas sp } \\
\text { Erwinia sp. } \\
\text { Enterobacter sp. } \\
\\
\text { - Gram-positivas } \\
\text { Bacillus sp. }\end{array}$ & $\begin{array}{c}\text { - Não fermentativas } \\
\text { Cryptococcus } s p \text {. } \\
\text { Rhodotorula } s p \\
\\
\text { - Fermentativas } \\
\text { Candida } s p . \\
\text { Kloeckera } s p .\end{array}$ & $\begin{array}{l}\text { Aureobasidium sp. } \\
\text { Fusarium sp. } \\
\text { Alternaria sp. } \\
\text { Epicoccum sp. } \\
\text { Mucor sp. } \\
\text { Chaetomium sp. } \\
\text { Rhizopus sp. } \\
\text { Phoma sp }\end{array}$ \\
\hline Frutas & & $\begin{array}{l}\text { Saccharomyces sp. } \\
\text { Hanseniaspora sp. } \\
\text { Pichia sp. } \\
\text { Kloeckera sp. } \\
\text { Candida sp. } \\
\text { Rodhotorula sp. }\end{array}$ & $\begin{array}{l}\text { Aspergillus sp. } \\
\text { Penicillium sp. } \\
\text { Mucor sp. } \\
\text { Alternaria sp. } \\
\text { Cladosporium sp. } \\
\text { Botrytis sp. } \\
\end{array}$ \\
\hline
\end{tabular}

Fonte: BRACKETT (1997).

As frutas apresentam maiores quantidades de açúcar e $\mathrm{pH}$ mais ácidos (4,6 ou menos), o que desfavorece o crescimento de bactérias, que não sejam as lácticas. Portanto, os fungos prevalecem nestes alimentos.

Os microrganismos Gram-positivos incluem as bactérias ácido lácticas, principalmente do gênero Leuconostoc, sp. e diversas leveduras (VAROQUAUX \& WILEY, 1997). As bactérias lácticas crescem em temperaturas superiores a $2{ }^{\circ} \mathrm{C}$ (VAROQUAUX \& WILEY, 1997). 
O metabolismo microbiano pode afetar a composição atmosférica no interior da embalagem, contribuindo para a alteração fisiológica do produto (VAROQUAUX \& WILEY, 1997).

\section{- Microrganismos deterioradores de alimentos}

Segundo BRACKETT (1997) alteração é qualquer modificação que torne o alimento indesejável para consumo. A degradação microbiológica é apenas uma das alterações, sendo as maiores perdas causadas por danos físicos.

As alterações microbiológicas podem ser classificadas como pré-colheita ou de campo e alterações pós-colheita. Todavia estas classificações podem levar a equívocos, visto que algumas alterações podem iniciar no período de pré-colheita, mas serem agravadas na pós-colheita. Por isto, outra forma de classificar as alterações microbiológicas seria mediante os sintomas apresentados (podridão úmida, podridão branda aquosa e podridão negra). Entretanto, mais uma vez a classificação deixa dúvida, pois o mesmo microrganismo pode produzir diversas alterações e diferentes microrganismos podem provocar as mesmas lesões. Assim, a melhor forma de classificar as alterações microbiológicas é a descrição do tipo de alteração pelo sintoma, complementada com o nome do microrganismo envolvido (BRACKETT, 1997).

Os microrganismo empregam diversos mecanismos para suplantar as defesas naturais das plantas. Um dos principais é a produção de enzimas pectinolíticas, como a pectinametilesterase e a poligalacturonase, e em segundo plano, hemicelulases, celulases e proteinases. Estas enzimas causam a liquefação dos tecidos (BRACKETT, 1997). Os microrganismos mais comuns que produzem estas enzimas são a Erwinia carotovora, Pseudomnas marginalis, Botrytis sp., Alternaria sp., Fusarium sp, e Colletotrichum sp. (BRACKETT, 1997). Não apenas o P. marginales, mas o gênero Pseudomonas sp. são produtores de pectinases (NGUYEN-THE \& CARLIN, 1994), o que significa que frutas e hortaliças são alvos destas enzimas deterioradoras microbianas.

Entre os patogênicos entéricos, Shigella $s p$. e Salmonella sp. podem ser veiculadas por frutas e hortaliças, mas encontram dificuldade para crescer sob refrigeração, podendo sobreviver por longos períodos nestas temperaturas. Assim, é importante evitar variações de temperaturas durante 0 armazenamento, pois temperaturas mais elevadas podem permitir o crescimento destes patógenos. No caso da Shigella sp. apenas 10 bactérias são suficientes para causar enfermidade (BRACKETT, 1997).

A Escherichia coli é um psicotrófico patogênico entérico que pode, tal qual a Salmonella $s p$. levar indivíduo à morte (BRACKETT, 1997). Outros dois psicotróficos patógenos importantes são Aeromonas hydrophila e Listeria monocytogenes (BRACKETT, 1997; NGUYEN-THE \& CARLIN, 1994). 
Diferentemente dos outros patógenos, a Aeromonas hydrophila está presente na maioria dos vegetais. Já a Listeria monocytogenes difere de todos os outros patógenos citados por ser gram-positiva. Sua letalidade em indivíduos susceptíveis, como crianças, idosos e gestantes pode ser de até $30 \%$, com manifestações semelhantes a meningites e encefalites. $O$ crescimento de L. monocytogenes é lento e dificultado sob atmosfera modificada (BRACKETT, 1997). Também gram-positivo é o Clostridium botulinum que pode crescer em baixas temperatura em concentrações muito reduzidas de oxigênio e pH moderado $(>4,6)$ (BRACKETT, 1997). Segundo DANIELS, KRISHNAMURTHI \& RIZVI (1985) o crescimento do microrganismo e a produção de toxina exigem pelo menos $3,3{ }^{\circ} \mathrm{C}$.

\section{- Hortaliças}

As bactérias são as principais deterioradoras de folhosos (NGUYEN-THE \& CARLIN, 1994) e, apesar da presença de gêneros muito diferentes, a maioria é gram-negativa. A Erwinia $s p$ é uma das mais agressivas, sobretudo a Erwinia carotovora, que geralmente provoca lesão branda e aquosa (BRACKETT, 1997). Outro tipo bastante comum é o gênero Pseudomonas $s p$. (NGUYEN-THE \& CARLIN, 1994), cujos sintomas são similares a Erwinia carotovora. Todavia seu crescimento é mais rápido e ocorre em temperaturas de refrigeração (BRACKETT, 1997). Dentre os Pseudomonas sp. o Pseudomonas fluorences representa de 50 a 90\%.

Bacilos e clostrídios também podem crescer, mas muito lentamente abaixo de $10^{\circ} \mathrm{C}$. Poucos são os fungos capazes de crescer em temperatura de refrigeração e provocar degradação em hortaliças. Entre eles estão Fusarium sp, Penicillium sp, Thamnidium $s p$ e Cladosporium $s p$ (BRACKETT, 1997).

Os maiores deterioradores de hortaliças são os psicotróficos, como Pseudomonas sp (BRACKETT, 1997). Algumas hortaliças apresentam mecanismos distintos contra alterações microbiológicas como a lignificação, processo que trata de cobrir o tecido lesado com novo tecido. Outro mecanismo importante de defesa das hortaliças, presente também nas frutas, é a produção de conservantes naturais. As fitoalexinas são exemplos bastante conhecidos de conservantes produzidos pelas plantas após sofrer infecção por certo microrganismo. $\mathrm{O}$ aipo produz a fitoalexina, denominada soraleno, como resposta a infecção de Sclerotinia sclerotiorum (BRACKETT, 1997).

\section{- Frutas}

Mais de 20 gêneros de fungos estão envolvidos na deterioração de frutas, como Alternaria sp., Botrytis sp., Penicillium sp. e Phytophthora sp., sendo alguns generalizados em várias frutas e outros específicos para determinado tipo de fruta. Em geral, as frutas são mais susceptíveis ao 
crescimento de fungos ao se tornarem mais maduras ou desidratadas (BRACKETT, 1997).

A casca das frutas constitui grande barreira contra as alterações microbiológicas. Certos fungos, como Geotrichum sp. e Rhizopus sp. exercem ação alteradora quando a mosca comum das frutas, Drosophila melanogaster, deposita esporos junto com seus ovos dentro das reentrâncias, comuns nas frutas. Outros microrganismos também são inseridos dentro das frutas após lesões causadas pelos ferrões dos insetos (BRACKETT, 1997).

\section{CONCLUSÃO}

Os alimentos minimamente processados vêm obtendo considerável participação no mercado de produtos frescos e "prontos para o consumo". Contudo, maior expansão neste segmento de mercado tem sido dificultada pela curta vida útil resultante de desordens fisiológicas, bioquímicas e microbiológicas a que estes produtos são susceptíveis. Neste sentido, é importante conhecer os efeitos causados pelo processamento mínimo para desenvolvimento de tecnologia que permita aumentar a vida útil dos produtos, mantendo as características nutricionais organolépticas e a seguridade do alimento. Para a manutenção destas características, é de suma importância o desenvolvimento de embalagens apropriadas para as características composicionais do produto.

\section{Abstract}

This article presents a brief review about physiological, biochemical and microbiological modifications that commonly occur in minimally processed foods. Concludes that the improvement of processing conditions and development of appropriate packages to the compositional characteristics of products, will provide a promising production of minimally processed foods.

\section{REFERÊNCIAS}

1 BRACKETT, R.E. Microbiological consequences of minimally processed fruits and vegetables. J. Food Proc. Pres., v.13, p.281292, 1989.

2 BRACKETT, R.E. Alteración microbiológicas y microorganismos patógenos de frutas y hortalizas refrigeradas mínimamente procesadas. In: WILEY, R.C. Frutas y hortalizas minimamente procesadas y refrigeradas. Zaragoza: Acribia, 1997. p. 263-304.

3 DANIELS, J.A.; KRISHNAMURTHI, R.; RIZVI, S.S.H. A review of effects of carbon dioxide on microbial growth and food quality. $J$. Food Protection, v. 48, n. 6, p. 532-537, 1985. 
4 HERNER, R.C. High $\mathrm{CO}_{2}$ effects of plant organs. In: WEICHMANN, J. Postharvest physiology of vegetables. New York: Marcel Dekker, 1987. p. 239-254.

5 HINTLIAN, C.B.; HOTCHKISS, J.H. The safety of modified atmosphere packaging: a review. Food Technology, v. 40, n. 12, p. 70-76, 1986.

6 HUXSOLL, C.C.; BOLIN, H.R. Processing and distribution alternatives for minimally processed fruits and vegetables. Food Technology, v. 43, n. 2, p.124-128, 1989.

7 KADER, A.A. Biochemical and physiological basis for effects of controlled and modified atmospheres on fruits and vegetables. Food Technology, v. 40, n. 5, p. 99-104, 1986.

8 KING JR., A.D.; BOLIN, H.R. Physiological and microbiological storage stability of minimally processed fruits and vegetables. Food Technology, v. 43, n. 2, p. 132-135, 1989.

9 LOUGHEED, E.C.; MURR, D.P.; TOIVONEN, P.M.A. Ethylene and nonethylene volatiles. In: WEICHMANN, J. Postharvest physiology of vegetables. New York: Marcel Dekker, 1987. p. 255-276.

10 MONNING, A. Studies on the reaction of Krebs cicle enzymes from apple tissue (cv.Cox Orange) to increased levels of $\mathrm{CO}_{2}$. Acta Horticultural, v. 138, p. 113-118, 1983.

11 NGUYEN-THE, C.; CARLIN, F. Microbiology of minimally processed fruits and vegetables. Critical Reviews in Food Science and Nutrition, v. 34, n. 4, p. 371-401, 1994.

12 VAROQUAUX, P.; WILEY, R.C. Cambios biológicos y bioquímicos en frutas y hortalizas refrigeradas minimamente procesadas. In: WILEY, R.C. Frutas y hortalizas minimamente procesadas y refrigeradas. Zaragoza: Acribia, 1997. p. 221-262.

13 WATADA, A. Effects of ethylene on the quality of fruits and vegetables. Food Technology, v. 40, n. 5, p. 82-85, 1986.

14 WATADA, A.E.; ABE, K.; YAMUCHI, N. Physiological activities of partially processed frutis and vegetables. Food Technology, v. 44, n. 5, p. 116-122, 1990

15 WATADA, A.E.; KO, N.P.; MINOTT, D.A. Factors affecting quality of fresh-cut horticultural products. Postharverst Biology and Technology, v. 9, p. 115-125, 1996.

16 WEICHMANN, J. Low oxigen effects. In: POSTHARVEST physiology of vegetables. New York: Marcel Dekker, 1987. p. 231-238. 